\title{
Crosstalk among DNA Damage, Mitochondrial Dysfunction, Impaired Mitophagy, Stem Cell Attrition, and Senescence in the Accelerated Ageing Disorder Werner Syndrome
}

\author{
Ruben Gudmundsrud $^{a}$ Tarjei H. Skjånes ${ }^{a}$ Brian C. Gilmour ${ }^{b}$ \\ Domenica Caponio $^{a}$ Sofie Lautrup ${ }^{a}$ Evandro F. Fang ${ }^{a}$ b \\ aDepartment of Clinical Molecular Biology, University of Oslo and Akershus University Hospital, Lørenskog, Norway; \\ bThe Norwegian Centre on Healthy Ageing (NO-Age), Oslo, Norway
}

\section{Keywords}

Werner syndrome $\cdot \mathrm{NAD}^{+} \cdot$ Ageing $\cdot$ Mitophagy $\cdot$ DNA repair $\cdot$ Accelerated ageing

\begin{abstract}
Werner syndrome (WS) is an accelerated ageing disease caused by multiple mutations in the gene encoding the Werner DNA helicase (WRN). The major clinical features of WS include wrinkles, grey hair, osteoporosis, and metabolic phenomena such as atherosclerosis, diabetes, and fatty liver, and resemble those seen in normal ageing, but occur earlier, in middle age. Defective DNA repair resulting from mutations in WRN explain the majority of the clinical features of WS, but the underlying mechanisms driving the larger metabolic dysfunction remain elusive. Recent studies in animal models of WS and in WS patient cells and blood samples suggest the involvement of impaired mitophagy, $\mathrm{NAD}^{+}$depletion, and accumulation of damaged mitochondria in metabolic dysfunction. This mini-review summarizes recent progress in the understanding of the molecular mechanisms of metabolic dysfunction in WS, with the involvement of DNA damage, mitochondrial dysfunction, mitophagy reduction,
\end{abstract}

stem cell impairment, and senescence. Future studies on $\mathrm{NAD}^{+}$and mitophagy may shed light on potential therapeutic strategies for the WS patients.

(c) 2021 The Author(s)

Published by S. Karger AG, Basel

\section{Werner Syndrome and Its Underlying Mechanisms}

Werner syndrome (WS) is a rare form of adult segmental progeria with clinical characteristics resembling those of normal ageing: greying of hair, wrinkling of skin, osteoporosis, atherosclerosis, cataracts, and certain metabolic features such as type II diabetes and changes in body fat distribution [Martin, 1997; Takemoto et al., 2013; Oshima et al., 2017; Shamanna et al., 2017; Yokote et al., 2017; Fang et al., 2019]. Patients usually live into their 50s, with their cause of death most often attributed to cancer or myocardial infarction [Huang et al., 2006; Goto et al., 2013].

WS is attributed to any mutation that causes a loss-offunction in the gene encoding the Werner protein (WRN),

R.G. and T.H.S. contributed equally to this work.

Correspondence to:

Evandro F. Fang, e.f.fang@medisin.uio.no

karger@karger.com www.karger.com/cgr

Karger $\stackrel{\text { ' }}{5}$

BOPEN ACCESS
(C) 2021 The Author(s)

Published by S. Karger AG, Basel

This is an Open Access article licensed under the Creative Commons Attribution-NonCommercial-4.0 International License (CC BY-NC) (http://www.karger.com/Services/OpenAccessLicense), applicable to the online version of the article only. Usage and distribution for commercial purposes requires written permission. 
a RecQ family DNA helicase with unique exonuclease activity [Yu et al., 1996; Gray et al., 1997; Brosh, 2013]. WRN is involved in a number of critical processes in healthy cells, such as DNA repair, replication, recombination, and telomere maintenance [Martin, 1997; Mukherjee et al., 2018]. Aberrant functioning of this protein is associated with genomic instability, senescence, and changes in nuclear morphology [summarized in recent reviews, e.g., Croteau et al., 2014; Shamanna et al., 2017; Yokote et al., 2017; Lautrup et al., 2019a]. In addition, WS cells are characterized by a short replicative life span and changes in heterochromatin [Salk et al., 1981; Zhang et al., 2015]. The resemblance of WS to human ageing has been firmly demonstrated, with WS linked to all 10 hallmarks of ageing [Lopez-Otin et al., 2013; Kennedy et al., 2014; Fang et al., 2017], and we have recently summarized this connection [Lautrup et al., 2019a]. These hallmarks include: DNA damage and defective DNA repair [Cheng et al., 2006], telomere attrition [Crabbe et al., 2007], epigenetic alterations [Maierhofer et al., 2017], deregulated nutrient sensing [Yasuda et al., 2010], loss of proteostasis [Zhu et al., 2015], altered cellular communication [Goto et al., 2015], cellular senescence [Grandori et al., 2003], stem cell exhaustion [Wu et al., 2018], mitochondrial dysfunction [Cogger et al., 2014], and impaired autophagy/mitophagy [Maity et al., 2014; Fang et al., 2019]. Dysfunctions in these 10 hallmarks are thought to be crucial in the ageing process.

Currently there is no cure for WS, but treatment of symptoms as they appear can improve patients' quality of life, and exploration of the molecular drivers of WS may shed light on new potential therapeutics. To this end, we here summarize recent progress in the molecular mechanisms of metabolic dysfunction in WS, focussing on DNA damage, impaired mitochondrial homoeostasis, stem cell exhaustion, and cellular senescence.

\section{Molecular Drivers of Accelerated Ageing in WS}

\section{Stem Cell Exhaustion}

Stem cell exhaustion is a defining hallmark of WS, as well as a key feature of both normal and pathological ageing. Lack of stem cells leads to immunosuppression, frailty, sarcopenia, and decreased wound healing [Lopez-Otin et al., 2013]. Ageing stem cells are characterized by a reduced capacity for self-renewal, a loss of proteostasis, and abnormal mitochondrial activity - including increased metabolic stress and production of higher levels of reactive oxygen species. Studies in haematopoietic stem cells suggest autophagy (including mitochondrial autophagy, termed mitophagy) is critical to maintain a low metabolic state and regenerative potential of young and old stem cells via clearing inactive and damaged mitochondria and other debris [Ho et al., 2017]. Autophagy and mitophagy are fundamental intracellular self-clearance systems responsible for delivering cytoplasmic/nuclear substrates and mitochondria to lysosomes for degradation [Rubinsztein et al., 2011], and restoration of the autophagy and mitophagy systems can ameliorate some of the negative effects of ageing [Rubinsztein et al., 2011; Fang et al., 2016; Kaushik and Cuervo, 2018]. Nicotinamide adenine dinucleotide $\left(\mathrm{NAD}^{+}\right.$, reduced form $\left.\mathrm{NADH}\right)$, is a fundamental molecule involved in bioenergetics, redox homoeostasis, genomic stability, mitochondrial homoeostasis, adaptive stress responses, and cellular survival [Canto et al., 2015; Verdin, 2015; Lautrup et al., 2019b]. Emerging experimental and clinical evidence suggests that $\mathrm{NAD}^{+}$levels are reduced in physiological ageing, accelerated ageing, and several ageing-related pathologies, such as Alzheimer's disease [Canto et al., 2015; Verdin, 2015; Lautrup et al., 2019b]. Thus $\mathrm{NAD}^{+}$is thought to have broad anti-ageing properties, with its enhancing effect on autophagy and mitophagy of special note, being able to promote mitochondrial homoeostasis and encourage cellular longevity [Fang et al., 2014; Fang, 2019], though $\mathrm{NAD}^{+}$affects many pathways which may also play important roles. We recently reported that supplementation of $\mathrm{NAD}^{+}$was able to rescue stem cell proliferation in the gut of Drosophila melanogaster fed a toxicant that otherwise induced stem cell exhaustion [Fang et al., 2019]. These findings suggest an important role for $\mathrm{NAD}^{+}$and the $\mathrm{NAD}^{+}$-mitophagy axis in stem cell selfrenewal and regeneration - verification of these results in WS patient stem cells presents an interesting direction for further research.

\section{DNA Damage and Genomic Instability}

DNA damage accumulates during lifetime and is a well-established hallmark of ageing [Lopez-Otin et al., 2013]. The crucial role of RecQ helicases in promoting DNA repair is well-expressed by their nickname: "guardians of the genome" [Chang et al., 2004; Brosh, 2013; Larsen and Hickson, 2013]. WRN is an important factor in many DNA repair pathways, including the repair of double-strand breaks by non-homologous end joining, homologous recombination (HR), and base excision repair [Croteau et al., 2014]. Post-translational modifications are necessary to activate and recruit WRN to sites of DNA damage, and during the DNA damage response, WRN is 
phosphorylated by several kinases, such as ATM, ATR, and CDK1. In classical non-homologous end joining, WRN is loaded onto blunt-end and cohesive-end complexes where it is phosphorylated by DNA-PKcs, allowing it to degrade DNA in a $3^{\prime}-5$ ' direction to facilitate ligation, while also protecting DNA strands from excessive degradation by MRE11 and CtIP [Brosh, 2013; Larsen and Hickson, 2013; Croteau et al., 2014; Shamanna et al., 2017]. Aberrant HR is observed in cells without WRN activity, thus WRN is thought to suppress illegitimate HR events [Shamanna et al., 2017].

The DNA damage seen in WS patients manifests early in pathogenesis and is characterized by changes in nuclear morphology, chromatin structure, and a variety of large and small chromosomal deletions and translocations. The overall genomic instability associated with WS gives WS patients a higher risk of developing cancer, and WS patients have higher frequencies of both epithelial (e.g., thyroid) and mesenchymal malignancies, with a ratio of 1:1 epithelial versus mesenchymal, in contrast to the 1:10 ratio seen in the general population [Brosh, 2013; Yokote et al., 2017]. This high occurrence of mesenchymal cancers - i.e., meningiomas, sarcomas, osteosarcomas, and certain myeloid malignancies - in WS patients is interesting when compared to the much lower rate seen in the population at large. This discrepancy may be explained by hyperactivation of the alternative lengthening of telomeres (ALT) pathway [Laud et al., 2005], as well as by changes in metabolism and redox homoeostasis [Pagano et al., 2005; Li et al., 2014]. Dysregulation of the ALT pathway occurs more often in mesenchymal malignancies, and it appears to be readily activated in the absence of WRN [De Vitis et al., 2018]. This suggests that targeting or rescuing of WRN may present a possible route for treating mesenchymal cancers, and further studies should be conducted to explore the interactions of WRN in carcinogenesis [Brosh, 2013; van Wietmarschen et al., 2020].

\section{Senescence}

WS is characterized by a high proportion of cells in a senescent state [Davis et al., 2007], a state defined by irreversible cell cycle arrest, changed morphology, and a senescence-associated secretory phenotype that results in the release of pro-inflammatory cytokines [Coppé et al., 2010]. Senescent cells contribute to ageing not only by accumulating in tissues, but also by limiting the regenerative potential of stem cell pools [Collado et al., 2007; Ho et al., 2017]. Keeping a healthy pool of stem cells is essential to maintaining tissue homoeostasis. As more and more stem cells enter a senescent state, the resultant in- flammation drives further senescence and cell death, compromising the tissue's ability to replenish.

As differentiated cells undergo cell division, the protective telomere caps on their chromosomes shorten, thus limiting the number of times a cell can divide before the telomeres are too short, resulting in a lack of replication potential and adoption of a senescent state [Hayflick and Moorhead, 1961]. Elongation of telomeres by telomerase or the ALT pathway can rescue cells from this fate [Crabbe et al., 2007].

Primary skin fibroblasts from WS patients and WRNdeficient cells undergo early replicative senescence [Salk et al., 1981], but the reprogramming of WS patient-derived cells into induced pluripotent stem cells (iPSCs) has revealed that such cells exhibit reduced genomic instability [Shimamoto et al., 2014]. This could be due to endogenous telomerase activity in the reprogrammed cells, underlying a strong interplay between WRN and telomere maintenance. Upon re-differentiation of WS iPSCs to mesenchymal stem cells (MSCs) the WS phenotype is recapitulated, including epigenetic and chromosomal structure alteration and premature loss of proliferative potential [Cheung et al., 2014]. These data demonstrate that the premature senescence observed in WS fibroblasts is likely due to an insufficient activity of telomerase.

The generation of iPSCs could shed light on possible mechanisms related to senescence in WS. The differentiation of human embryonic stem cells has been used to generate a model of WS that can be studied as they differentiated into MSCs, as above. During long-term passaging, WRN-deficient cells recapitulate the ageing phenotype, including loss of proliferative potential and premature senescence. A similar case is seen with cultured WS fibroblasts, with several markers associated with senescence being upregulated, including: $16^{\text {Ink4a }}, \mathrm{p} 21^{\text {Waf1 }}$, as well as increased numbers of cells positive for senescence-associated $\beta$-galactosidase (SA- $\beta$-gal) and a higher proportion of senescence-associated secretory phenotype cells [Zhang et al., 2015]. However, a lack of premature senescence is observed in neural stem cells, keratinocytes, and endothelial cells in WS, pointing to the possibility of tissue- and cell type-specific sensitivities to senescence in the absence of WRN protein.

Changes in chromatin structure are observed in senescent cells, and WRN has been shown to associate with proteins which are important for heterochromatin formation, such as SUV39H1 and HPa. Loss of catalytic function in SUV39H1 in WT cells leads to a phenotype that resembles the phenotype in Wrn knockout cells. These cells display a severe disruption in $\mathrm{H} 3 \mathrm{~K} 9 \mathrm{Me} 3$ his- 
tone marks [Zhang et al., 2015]. Heterochromatin disruption has also been seen in normal aged MSCs [Zhang et al., 2015]. This could implicate disrupted heterochromatin as a driver of both pathological and physiological ageing.

\section{Mitochondrial Dysfunction and Impaired Mitophagy}

As metabolic changes, such as atherosclerosis and hypertriglyceridemia, are seen in WS patients, it is expected to observe changes in the liver and mitochondria. Mice lacking a functional Werner helicase domain $\left(\mathrm{Wr}^{\Delta h e l / \Delta h e l}\right)$ show many morphological changes in the liver as well as changes in mitochondrial morphology, number, and function. This $\mathrm{Wrn}^{\Delta h e l / \Delta h e l}$ model shows mitochondrial dysfunction, confirmed by Seahorse technology as increased respiration rate and uncoupling, as well as morphological changes in mitochondrial volume, as confirmed by electron microscopy [Cogger et al., 2014]. However, compared with matched WT littermates, there is no detectable impairment of mitochondrial function in mouse embryonic fibroblasts, heart, brain, or liver tissues from $\mathrm{Wrn}^{-/-}$(WRN knockout) mice; this shortcoming may be explained by the long telomeres seen in mice, which may reduce the pathological seriousness of impaired DNA repair and telomere maintenance occurring from loss of WRN [Fang et al., 2019]. Unlike the variability of mitochondrial states in different mouse models of WS, primary cells from WS patients harbouring various genetic mutations consistently show impaired mitochondrial function [Fang et al., 2019].

WRN has been associated with the machinery of the autophagy system, with the acidic domain of WRN being critical for autophagy [Maity et al., 2018], and cells lacking a functional WRN show reduced autophagic responses during starvation [Maity et al., 2014]. Recently, impaired mitophagy was reported in WS, with restoration of mitophagy improving disease phenotypes in both Caenorhabditis elegans and D. melanogaster models of WS, as well as in primary fibroblasts from WS patients; this strongly suggests that a DNA damage-induced impairment of the $\mathrm{NAD}^{+}$-mitophagy axis plays a pivotal role in initiation and progression of WS [Fang et al., 2019]. Impairment of mitophagy results in both an impaired metabolic state and an increase in oxidative stress, this results in activation of a senescence programme called mitochondrial dysfunction-associated senescence. This senescent state differs from others by a reduced $\mathrm{NAD}^{+} / \mathrm{NADH}$ ratio and its unique secretory phenotype [Wiley et al., 2016]. Indeed, $\mathrm{NAD}^{+}$augmentation delayed, although did not stop, the senescence phenotype in a cell culture system [Wiley et al., 2016]. Collectively, evidence linking mitochondrial dysfunction and defective mitophagy in WS points to a likely causative linkage to mitochondriaoriented senescence and inflammation.

\section{Telomere Attrition}

Telomeres shield the termini of DNA, but shorten as we age, acting as the Achille's heel of the genomic system [Harley et al., 1990]. These telomeric caps consist of TTAGGG repeats looped back on themselves in a T-loop, with a G-rich overhang that invades the double strand and forms a D-loop [Greider, 1999]. This structure is essential for protecting the otherwise blunt ends of DNA so they cannot be mistaken for dsDNA breaks, which would lead to their subsequent degradation, and the subsequent activation of the DNA damage response, possibly leading to senescence [d'Adda di Fagagna et al., 2003; Longhese, 2008]. Formation of this protective telomeric structure is facilitated by the shelterin complex, consisting of the proteins TRF1, TRF2, RAP1, POT1, TPP1, and TIN2 [Cheung et al., 2014]. Limitations imposed by replication machinery mean that segments of telomeres are lost with every cell division. As telomeres become too short, healthy cells undergo cell cycle arrest and may develop a senescent phenotype to prevent degradation of the coding regions of the genome [Levy et al., 1992]. Some cells in the body can extend the length of telomeres through activation of usually dormant telomerase or through the ALT pathway.

WRN plays an important role in telomere maintenance, and $W R N$ mutation-induced telomere attrition contributes to many of the ageing features seen in WS patients. This role is coordinated by the interaction of WRN with TRF1, TRF2, and POT1. WRN's helicase and exonuclease activities can then cooperate to resolve D-loops [Opresko et al., 2004]. Interestingly, the expression levels of these genes also differ between WS and WT cells.

Accelerated senescence and telomere shortening contribute to accelerated ageing in WS. Additionally, telomere rearrangements have been well-documented in WS and WRN-deficient cells [Crabbe et al., 2007]. Reprogramming of WS fibroblasts to iPSCs results in elongated telomeres and the suppression of telomere dysfunction. However, upon reprogramming to MSCs, telomeric dysfunction and premature senescence re-occur [Shimamoto et al., 2014]. The WS phenotype in MSCs was ameliorated by expression of hTERT, probably due to elongation of telomeres, or knockdown of p53 - both of which are known to reduce senescence [Cheung et al., 2014] - at the cost of increased susceptibility to genomic instability 


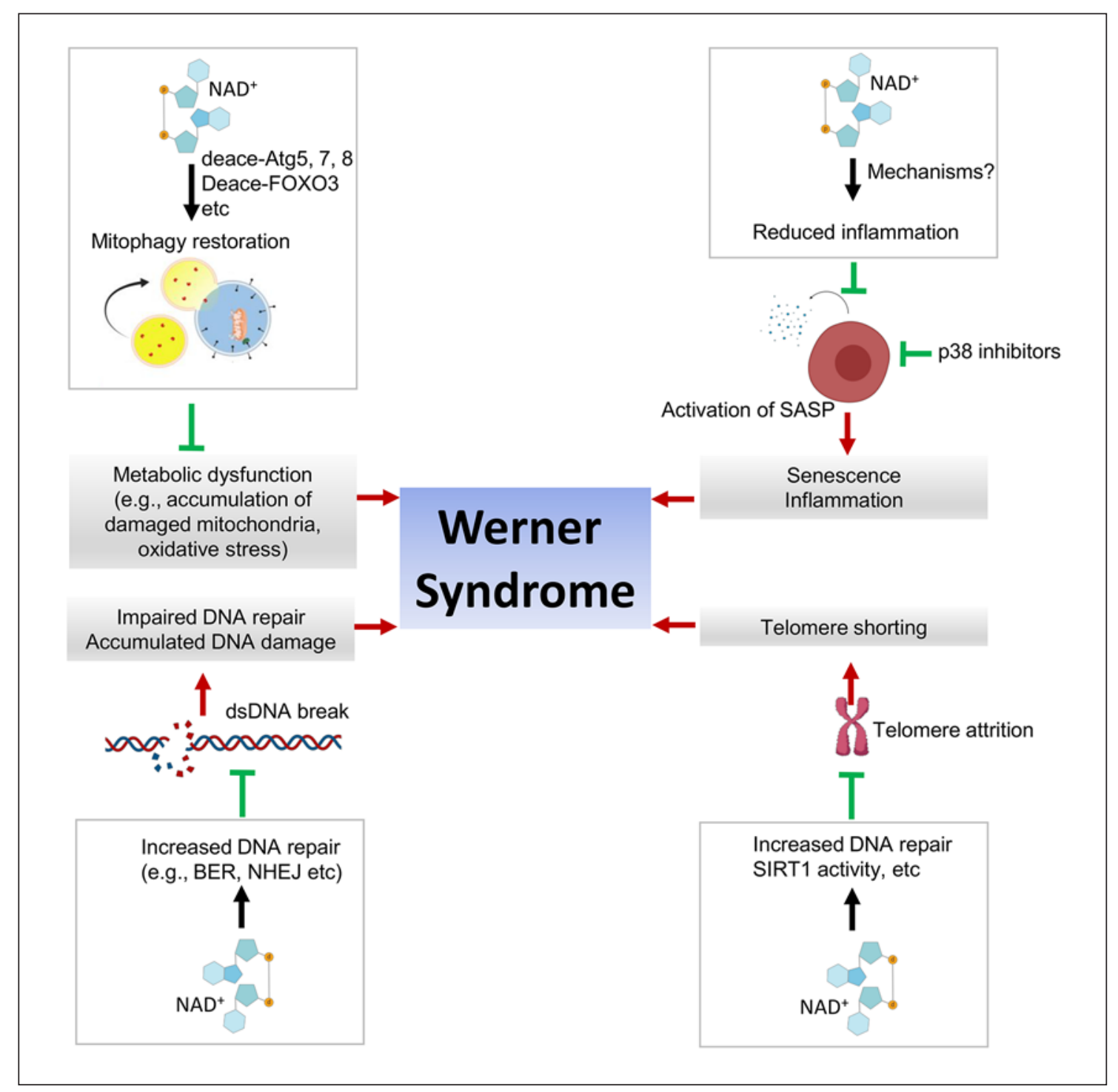

Fig. 1. A simplified summary of certain major molecular drivers of Werner syndrome (WS) and roles of $\mathrm{NAD}^{+}$ augmentation in ameliorating the drivers of WS pathology. Here we focus on how DNA damage, telomere attrition, cellular senescence, and metabolic dysfunction contribute to WS (red arrows). We also summarize mechanistic possibilities how $\mathrm{NAD}^{+}$and p38 inhibitors may alleviate (green). See text for details and references.

and an increased likelihood of tumourigenesis. In the absence of telomerase, ALT cells and WRN-deficient cells show an increase in telomere-sister chromatid exchanges which, in part, suggests that the absence of WRN facilitates ALT pathway activation and may explain the high occurrence of ALT mutations and mesenchymal malignancies seen in WS patients [Shamanna et al., 2016]. A clear link between WRN and telomere maintenance has also been described in mice, and indeed $\mathrm{Terc}^{-/-} / \mathrm{Wrn}^{-/-}$ mice display a phenotype similar to human WS [Chang, 2005].

Mitochondrial Dysfunction and Senescence in Werner Syndrome

\section{Interventional Strategies for WS}

Currently there is no known cure for WS, though potential therapeutics and strategies continue to emerge. Current treatments focus on the alleviation of symptoms as they appear in each individual patient. These range from managing diabetes through dietary changes, to eye surgery for cataracts, and intense chemotherapy for treating malignancies. WS patients are prone to certain diseases, such as atherosclerosis, and thus require close follow-up [Oshima et al., 2017; Yokote et al., 2017]. 
Mitogen-activated protein kinases (MAPKs), already attractive targets in cancer, have recently been investigated as potential targets for treatment of WS [Bagley et al., 2010], and there is evidence for the involvement of the MAPK p38 in the induction of senescence [Wang et al., 2002; Iwasa et al., 2003]. Furthermore, p38 inhibitors have already shown promise in inhibiting models of senescence, suggesting that they may be candidate treatments in diseases of accelerated ageing such as WS [Alimbetov et al., 2016]. Davis et al. [2016] have already shown that inhibition of $\mathrm{p} 38$ ameliorated the slow growth and altered morphology seen in WS fibroblasts [Opresko et al., 2005], and such compounds are being investigated for clinical use.

More all-purpose candidates for therapeutics against WS include the use of vitamin C, itself targeting MAPK pathways and inhibiting senescence. Vitamin $\mathrm{C}$ has been shown to extend mean lifespan and to reverse agerelated defects in both C. elegans and mouse models of WS [Massip et al., 2010; Dallaire et al., 2014]. Promising data have also been generated in WRN-deficient MSCs, in which it promoted a larger change in the cells' transcriptome and affected pathways and genes linked to ageing [Li et al., 2016]. The shortened replicative life span and premature senescence observed in these cultures recapitulates the accelerated ageing seen in WS patients, and is thought to originate from genomic instability and oxidative stress, causing larger cellular stress - this in turn activates stress kinases such as the MAPKs p38 and JNK [Davis et al., 2007], again emphasizing their potential as targets.

Impairment of the $\mathrm{NAD}^{+}$-mitophagy axis has recently been linked to WS aetiology, opening up restoration of this axis as a possible therapeutic strategy. Crucial to the functioning of this axis is the small molecule $\mathrm{NAD}^{+}$, which has already shown promise as a new way to ameliorate the symptoms found in cross-species animal models of both normal and accelerated ageing through restoration of this axis [Fang et al., 2014, 2016; Verdin, 2015].

In addition to the increased DNA damage seen in WS, a driver of the disease is metabolic impairment linked to mitochondrial dysfunction - this may partially result from impaired mitophagy and the depletion of $\mathrm{NAD}^{+}$. $\mathrm{NAD}^{+}$supplementation, in both C. elegans and D. melanogaster models of WS, was found to increase lifespan and reduce accelerated ageing via DCT-1- and ULK1-dependent mitophagy pathways [Fang et al., 2019]. Mitophagy-dependent mitochondrial quality control also regulates fat metabolism and stem cell maintenance. Based on this study, a crossover clinical trial in WS pa- tients with a treatment containing nicotinamide riboside, a NAD ${ }^{+}$precursor, is in progress in Japan (NIPH Clinical Trials, JRCT ID: jRCTs031190141).

\section{Conclusions and Future Perspectives}

WS is a unique model for the study of ageing. Several studies demonstrated how it recapitulates the hallmarks of normal ageing, but further study is needed to reveal unknown regulatory mechanisms linking WRN dysfunction and ageing. Among many driving factors, here we have summarized evidence showing how stem cell dysfunction, DNA damage, cellular senescence, telomere attrition, and metabolic dysfunction contribute to WS; we have also summarized mechanistic possibilities for how $\mathrm{NAD}^{+}$alleviates these features (summarized in Fig. 1). Senescence is also linked to other hallmarks of ageing, such as telomere attrition and mitochondrial dysfunction. All these data demonstrate that deficits in DNA repair, telomere shortening, and epigenetic alterations due to WRN loss promote premature cellular senescence. Therapeutic strategies targeting one or more of such hallmarks of ageing have been postulated for WS patients. Currently, clinical trials using nicotinamide riboside are ongoing on age-related diseases such as diabetes, neurodegenerative diseases, and certain premature ageing diseases, such as Cockayne syndrome and ataxia telangiectasia [Lautrup et al., 2019b; Gilmour et al., 2020]. Future work should prioritize the development of novel WS laboratory models, such as the use of iPSC-differentiated 3D organoids, and focus on in-depth mechanistic studies and novel drug development. Clinical trials for any such novel drug candidates should then be carried out to determine their ability to treat WS.

\section{Acknowledgements}

The authors acknowledge the valuable work of the many investigators whose published articles they were unable to cite owing to space limitations. The authors thank Dr. Vilhelm Bohr at the NIA and University of Copenhagen for reading of the manuscript. Some components of Figure 1 were generated using the software BioRender.

\section{Conflict of Interest Statement}

E.F.F. has CRADA arrangements with ChromaDex and is consultant to Aladdin Healthcare Technologies and the Vancouver Dementia Prevention Centre. The rest of the authors have no conflicts of interest to declare. 


\section{Funding Sources}

E.F.F. is supported by Helse Sør-Øst (\#2017056, \#2020001), the Research Council of Norway (\#262175 and \#277813), the National Natural Science Foundation of China (\#81971327), an Akershus University Hospital Strategic grant (\#269901), and a Rosa Sløyfe grant (\#207819) from the Norwegian Cancer Society.

\section{Author Contributions}

E.F.F. designed the project; R.G., T.H.S., B.C.G., and D.C. did the literature research and wrote the review. D.C., S.L., and E.F.F. reviewed the manuscript.

\section{References}

Alimbetov D, Davis T, Brook AJ, Cox LS, Faragher RG, Nurgozhin T, et al. Suppression of the senescence-associated secretory phenotype (SASP) in human fibroblasts using small molecule inhibitors of p38 MAP kinase and MK2. Biogerontology. 2016;17:305-15.

Bagley MC, Davis T, Murziani PG, Widdowson CS, Kipling D. Use of p38 MAPK Inhibitors for the Treatment of Werner Syndrome. Pharmaceuticals (Basel). 2010;3:1842-72.

Brosh RM Jr. DNA helicases involved in DNA repair and their roles in cancer. Nat Rev Cancer. 2013;13:542-58.

Canto C, Menzies KJ, Auwerx J. NAD(+) Metabolism and the Control of Energy Homeostasis: A Balancing Act between Mitochondria and the Nucleus. Cell Metab. 2015;22:31-53.

Chang S. A mouse model of Werner Syndrome: what can it tell us about aging and cancer? Int J Biochem Cell Biol. 2005;37:991-9.

Chang S, Multani AS, Cabrera NG, Naylor ML, Laud P, Lombard D, et al. Essential role of limiting telomeres in the pathogenesis of Werner syndrome. Nat Genet. 2004;36:877-82.

Cheng WH, Kusumoto R, Opresko PL, Sui X, Huang S, Nicolette ML, et al. Collaboration of Werner syndrome protein and BRCA1 in cellular responses to DNA interstrand crosslinks. Nucleic Acids Res. 2006;34:2751-60.

Cheung HH, Liu X, Canterel-Thouennon L, Li L, Edmonson C, Rennert OM. Telomerase protects Werner syndrome lineage-specific stem cells from premature aging. Stem Cell Reports. 2014;2:534-46.

Cogger VC, Svistounov D, Warren A, Zykova S, Melvin RG, Solon-Biet SM, et al. Liver aging and pseudocapillarization in a Werner syndrome mouse model. J Gerontol A Biol Sci Med Sci. 2014;69:1076-86.

Collado M, Blasco MA, Serrano M. Cellular senescence in cancer and aging. Cell. 2007;130: 223-33.

Coppé JP, Desprez PY, Krtolica A, Campisi J. The senescence-associated secretory phenotype: the dark side of tumor suppression. Annu Rev Pathol. 2010;5:99-118.

Crabbe L, Jauch A, Naeger CM, Holtgreve-Grez $\mathrm{H}$, Karlseder J. Telomere dysfunction as a cause of genomic instability in Werner syndrome. Proc Natl Acad Sci USA. 2007;104: 2205-10.

Croteau DL, Popuri V, Opresko PL, Bohr VA. Human RecQ helicases in DNA repair, recombination, and replication. Annu Rev Biochem. 2014;83:519-52.
d'Adda di Fagagna F, Reaper PM, Clay-Farrace L, Fiegler H, Carr P, von Zglinicki T, et al. A DNA damage checkpoint response in telomere-initiated senescence. Nature. 2003;426: 194-8.

Dallaire A, Proulx S, Simard MJ, Lebel M. Expression profile of Caenorhabditis elegans mutant for the Werner syndrome gene ortholog reveals the impact of vitamin C on development to increase life span. BMC Genomics. 2014; 15:940.

Davis T, Wyllie FS, Rokicki MJ, Bagley MC, Kipling D. The role of cellular senescence in Werner syndrome: toward therapeutic intervention in human premature aging. Ann N Y Acad Sci. 2007;1100:455-69.

Davis T, Brook AJ, Rokicki MJ, Bagley MC, Kipling D. Evaluating the Role of p 38 MAPK in the Accelerated Cell Senescence of Werner Syndrome Fibroblasts. Pharmaceuticals (Basel). 2016;9(2):23.

De Vitis M, Berardinelli F, Sgura A. Telomere Length Maintenance in Cancer: At the Crossroad between Telomerase and Alternative Lengthening of Telomeres (ALT). Int J Mol Sci. 2018;19(2):606.

Fang EF. Mitophagy and $\mathrm{NAD}(+)$ inhibit Alzheimer disease. Autophagy. 2019;15:1112-4.

Fang EF, Scheibye-Knudsen M, Brace LE, Kassahun $\mathrm{H}$, SenGupta T, Nilsen H, et al. Defective mitophagy in XPA via PARP-1 hyperactivation and $\mathrm{NAD}(+) / S I R T 1$ reduction. Cell. 2014;157:882-96.

Fang EF, Scheibye-Knudsen M, Chua KF, Mattson MP, Croteau DL, Bohr VA. Nuclear DNA damage signalling to mitochondria in ageing. Nat Rev Mol Cell Biol. 2016;17:308-21.

Fang EF, Lautrup S, Hou Y, Demarest TG, Croteau DL, Mattson MP, et al. NAD+ in Aging: Molecular Mechanisms and Translational Implications. Trends Mol Med. 2017;23(10): 899-916.

Fang EF, Hou Y, Lautrup S, Jensen MB, Yang B, SenGupta T, et al. NAD $(+)$ augmentation restores mitophagy and limits accelerated aging in Werner syndrome. Nat Commun. 2019; 10(1):5284.

Gilmour BC, Gudmundsrud R, Frank J, Hov A, Hindkjaer Lautrup S, Aman Y, et al. Targeting $\mathrm{NAD}(+)$ in translational research to relieve diseases and conditions of metabolic stress and ageing. Mech Ageing Dev. 2020;186: 111208.

Goto M, Ishikawa Y, Sugimoto M, Furuichi Y. Werner syndrome: a changing pattern of clin- ical manifestations in Japan (1917 2008). Biosci Trends. 2013;7:13-22.

Goto M, Hayata K, Chiba J, Matsuura M, IwakiEgawa S, Watanabe Y. Multiplex cytokine analysis of Werner syndrome. Intractable Rare Dis Res. 2015;4:190-7.

Grandori C, Wu KJ, Fernandez P, Ngouenet C, Grim J, Clurman BE, et al. Werner syndrome protein limits MYC-induced cellular senescence. Genes Dev. 2003;17:1569-74.

Gray MD, Shen JC, Kamath-Loeb AS, Blank A, Sopher BL, Martin GM, et al. The Werner syndrome protein is a DNA helicase. Nat Genet. 1997;17:100-3.

Greider CW. Telomeres do D-loop-T-loop. Cell. 1999;97(4):419-22.

Harley CB, Futcher AB, Greider CW. Telomeres shorten during ageing of human fibroblasts. Nature. 1990;345:458-60.

Hayflick L, Moorhead PS. The serial cultivation of human diploid cell strains. Exp Cell Res. 1961; 25:585-621.

Ho TT, Warr MR, Adelman ER, Lansinger OM, Flach J, Verovskaya EV, et al. Autophagy maintains the metabolism and function of young and old stem cells. Nature. 2017;543: 205-10.

Huang S, Lee L, Hanson NB, Lenaerts C, Hoehn $\mathrm{H}$, Poot M, et al. The spectrum of WRN mutations in Werner syndrome patients. Hum Mutat. 2006;27:558-67.

Iwasa $\mathrm{H}$, Han J, Ishikawa F. Mitogen-activated protein kinase p38 defines the common senescence-signalling pathway. Genes Cells. 2003;8:131-44.

Kaushik S, Cuervo AM. The coming of age of chaperone-mediated autophagy. Nat Rev Mol Cell Biol. 2018;19:365-81.

Kennedy BK, Berger SL, Brunet A, Campisi J, Cuervo AM, Epel ES, et al. Geroscience: linking aging to chronic disease. Cell. 2014;159:709-13.

Larsen NB, Hickson ID. RecQ Helicases: Conserved Guardians of Genomic Integrity. Adv Exp Med Biol. 2013;767:161-84.

Laud PR, Multani AS, Bailey SM, Wu L, Ma J, Kingsley C, et al. Elevated telomere-telomere recombination in WRN-deficient, telomere dysfunctional cells promotes escape from senescence and engagement of the ALT pathway. Genes Dev. 2005;19:2560-70.

Lautrup S, Caponio D, Cheung HH, Piccoli C, Stevnsner T, Chan WY, et al. Studying Werner syndrome to elucidate mechanisms and therapeutics of human aging and age-related diseases. Biogerontology. 2019a;20:255-69. 
Lautrup S, Sinclair DA, Mattson MP, Fang EF. $\mathrm{NAD}(+)$ in Brain Aging and Neurodegenerative Disorders. Cell Metab. 2019b;30:630-55.

Levy MZ, Allsopp RC, Futcher AB, Greider CW, Harley CB. Telomere end-replication problem and cell aging. J Mol Biol. 1992;225:95160.

Li B, Iglesias-Pedraz JM, Chen L-Y, Yin F, Cadenas E, Reddy S, et al. Downregulation of the Werner syndrome protein induces a metabolic shift that compromises redox homeostasis and limits proliferation of cancer cells. Aging Cell. 2014;13:367-78.

Li Y, Zhang W, Chang L, Han Y, Sun L, Gong X, et al. Vitamin $\mathrm{C}$ alleviates aging defects in a stem cell model for Werner syndrome. Protein Cell. 2016;7:478-88.

Longhese MP. DNA damage response at functional and dysfunctional telomeres. Genes Dev. 2008;22:125-40.

Lopez-Otin C, Blasco MA, Partridge L, Serrano M, Kroemer G. The hallmarks of aging. Cell. 2013;153:1194-217.

Maierhofer A, Flunkert J, Oshima J, Martin GM, Haaf T, Horvath S. Accelerated epigenetic aging in Werner syndrome. Aging (Albany NY). 2017;9:1143-52.

Maity J, Bohr VA, Laskar A, Karmakar P. Transient overexpression of Werner protein rescues starvation induced autophagy in Werner syndrome cells. Biochim Biophys Acta. 2014; 1842:2387-94.

Maity J, Das B, Bohr VA, Karmakar P. Acidic domain of WRNp is critical for autophagy and up-regulates age associated proteins. DNA Repair (Amst). 2018;68:1-11.

Martin GM. The Werner mutation: does it lead to a "public" or "private" mechanism of aging? Mol Med. 1997;3(6):356-8.

Massip L, Garand C, Paquet ER, Cogger VC, O'Reilly JN, Tworek L, et al. Vitamin C restores healthy aging in a mouse model for Werner syndrome. FASEB J. 2010;24:158-72.

Mukherjee S, Sinha D, Bhattacharya S, Srinivasan K, Abdisalaam S, Asaithamby A. Werner Syndrome Protein and DNA Replication. Int J Mol Sci. 2018;19:3442.
Opresko PL, Otterlei M, Graakjaer J, Bruheim P, Dawut L, Kølvraa S, et al. The Werner syndrome helicase and exonuclease cooperate to resolve telomeric $\mathrm{D}$ loops in a manner regulated by TRF1 and TRF2. Mol Cell. 2004;14: 763-74.

Opresko PL, Mason PA, Podell ER, Lei M, Hickson ID, Cech TR, et al. POT1 stimulates RecQ helicases WRN and BLM to unwind telomeric DNA substrates. J Biol Chem. 2005;280: 32069-80.

Oshima J, Sidorova JM, Monnat RJ Jr. Werner syndrome: Clinical features, pathogenesis and potential therapeutic interventions. Ageing Res Rev. 2017;33:105-14.

Pagano G, Zatterale A, Degan P, d'Ischia M, Kelly $\mathrm{F}$, Pallardó $\mathrm{F}$, et al. In vivo prooxidant state in Werner syndrome (WS): Results from three WS patients and two WS heterozygotes. Free Radic Res. 2005;39:529-33.

Rubinsztein DC, Marino G, Kroemer G. Autophagy and aging. Cell. 2011;146:682-95.

Salk D, Bryant E, Au K, Hoehn H, Martin GM. Systematic growth studies, cocultivation, and cell hybridization studies of Werner syndrome cultured skin fibroblasts. Hum Genet. 1981;58:310-6.

Shamanna RA, Lu H, de Freitas JK, Tian J, Croteau DL, Bohr VA. WRN regulates pathway choice between classical and alternative nonhomologous end joining. Nat Commun. 2016;7:13785

Shamanna RA, Croteau DL, Lee JH, Bohr VA. Recent Advances in Understanding Werner Syndrome. F1000Res. 2017;6:1779.

Shimamoto A, Kagawa H, Zensho K, Sera Y, Kazuki Y, Osaki M, et al. Reprogramming suppresses premature senescence phenotypes of Werner syndrome cells and maintains chromosomal stability over long-term culture. PLoS One. 2014;9:e112900.

Takemoto M, Mori S, Kuzuya M, Yoshimoto S, Shimamoto A, Igarashi M, et al. Diagnostic criteria for Werner syndrome based on Japanese nationwide epidemiological survey. Geriatr Gerontol Int. 2013;13:475-81. van Wietmarschen N, Sridharan S, Nathan WJ, Tubbs A, Chan EM, Callen E, et al. Repeat expansions confer WRN dependence in microsatellite-unstable cancers. Nature. 2020;586: 292-8.

Verdin E. $\mathrm{NAD}(+)$ in aging, metabolism, and neurodegeneration. Science. 2015;350:120813.

Wang W, Chen JX, Liao R, Deng Q, Zhou JJ, Huang S, et al. Sequential activation of the MEK-extracellular signal-regulated kinase and MKK3/6-p38 mitogen-activated protein kinase pathways mediates oncogenic ras-induced premature senescence. Mol Cell Biol. 2002;22:3389-403.

Wiley CD, Velarde MC, Lecot P, Liu S, Sarnoski EA, Freund A, et al. Mitochondrial Dysfunction Induces Senescence with a Distinct Secretory Phenotype. Cell Metab. 2016;23:30314.

Wu Z, Zhang W, Song M, Wang W, Wei G, Li W, et al. Differential stem cell aging kinetics in Hutchinson-Gilford progeria syndrome and Werner syndrome. Protein Cell. 2018;9:33350.

Yasuda H, Nagata M, Hara K, Moriyama H, Yokono K. Biguanide, but not thiazolidinedione, improved insulin resistance in Werner syndrome. J Am Geriatr Soc. 2010;58:181-2.

Yokote K, Chanprasert S, Lee L, Eirich K, Takemoto M, Watanabe A, et al. WRN Mutation Update: Mutation Spectrum, Patient Registries, and Translational Prospects. Hum Mutat. 2017;38:7-15.

Yu CE, Oshima J, Fu YH, Wijsman EM, Hisama F, Alisch R, et al. Positional cloning of the Werner's syndrome gene. Science. 1996;272: 258-62.

Zhang W, Li J, Suzuki K, Qu J, Wang P, Zhou J, et al. Aging stem cells. A Werner syndrome stem cell model unveils heterochromatin alterations as a driver of human aging. Science. 2015;348:1160-3.

Zhu X, Zhang G, Kang L, Guan H. Epigenetic Regulation of Werner Syndrome Gene in Age-Related Cataract. J Ophthalmol. 2015; 2015:579695 